\title{
VLT: A sustainable solution to urban mobility, in João Pessoa-PB
}

\author{
Uiara Wasconcelos de Assis ${ }^{\mathrm{a},}$, Glaucia Wasconcelos Silva ${ }^{\mathrm{b}}$ \\ a After Interior Design, IESB, Institute of Higher Education of Brasilia, uiara_assis@hotmail.com, SGAN 609 - \\ Group D - L2 Av Norte, Brasilia (DF), Brazil \\ ${ }^{\mathrm{b}}$ Liberal Profissional - Dental Ergonomics-Ms, glauciaws@yahoo.com.br,Av Flávio Ribeiro Coutinho, 300,room \\ 101, Bessa, Joao Pessoa (PB), Brazil
}

\begin{abstract}
The changes happen quickly in today's world, simultaneously interacting with technological advances in the sciences and new paradigms socio-political and economic, in search of a sustainable future and a present with emergency strategies for the preservation of humanity and the planet "Earth ". Currently, the mobility of people in the intra-urban space is being threatened by congestion, pollution resulting from the appreciation of the culture of personal transport and the precariousness of public transportation. In the city of João Pessoa (PB), the subject of this finding for these disorders. Workers suffer the consequences of daily stress takes to access home-work, difficulty in arriving at the right time to the workplace and adverse reactions caused by pollution. The VLT (Light Rail Vehicle) has been presented as a viable solution to the problems of public transport, with several experiments that can be seen as positive in the world. This work involves the implementation of a public transport system based on VLT Corridor along the Avenue Dom Pedro II, in João Pessoa (PB), aiming to acquire a good transport network for use of the population, reduce the number of vehicles on process, minimize pollution and optimize urban mobility.
\end{abstract}

Keywords: Congestion, Transport, VLT, Population

\section{Introduction}

The changes happen quickly in today's world, in conjunction with technological advances, interacting with science, education, economics, politics, the arts, in search of a sustainable future and a present, with strategies for emergency the preservation of man, nature and the planet "Earth.

"The disorderly growth of medium and large Brazilian cities has caused various damages, with respect to the quality of life. It presents housing deficit, the problems related to infrastructure, health and education, and transport, which have preoccupied planners and managers.

Currently, the mobility of people in the intra-urban space is being threatened by congestion, in the center and main streets, mainly in peak hours, or by the poor public transport or by the appreciation of the culture of individual transport.

In Brazil you can see the introduction of some concepts and practices based in urban American sub- urbs, and other models which contribute to urban sprawl. The class migrate to more affluent areas distant from the center, concurrently, the subdivisions and popular assemblies, are also being leased in areas equally spaced, forming a new model center - periphery. The center holds most of the public services and trade, thus contributing to the usual shift of the population living farther to the central area, clogging the road system and especially the radial road standards.

[3] The rail transportation, specifically the VLT, has been proposed as a viable solution to the problems of public transport, with several experiments that can be seen as positive in the world, like Tokyo (Japan), Hong Kong (China) Calcutta (India), San Francisco (USA), and several European cities: Amsterdam, the Netherlands, Geneva, Switzerland, Nantes, Strasbourg, Bordeaux, Orleans, Nice, France, Germany Kalrsruhe, among others.

Joao Pessoa $(\mathrm{PB})$, the subject of this finding is the large increase in the use of private cars, circulating in the main corridor and city center, especially in times 
of "peak", where we observe signs of saturation, congestion, pollution, slow traffic.

Workers suffer daily inconvenience to come to their places of work, and the "stress", the delay on the way home - job the demands of work and schedule compliance on the part of employers. Diseases arise respiratory, allergies and other losses from pollution, release of carbon monoxide, a substance harmful to people.

It is noticed that in recent years, has been increasing efforts to reeducate the population to take positions that respect and preserve life on Earth. This fact can be verified in various systems of communication, through which man is invited to be "environmentally friendly".

However, in most cases, people still do not realize that the ways of acting, of being and living, could impact negatively on the preservation of nature and therefore, the survival of human beings.

This work is the creation of a viable proposal for the establishment of a public transport system based on the VLT (Vehicle Take it to them on Tri), along the Corridor of Avenue Dom Pedro II, in João Pessoa (PB). This avenue begins in Joao Pessoa Square, the downtown area, and runs through the center and the neighborhood of the Tower until the entrance of the Universidade Federal da Paraíba. It consists of a binary, which corresponds to Avenue Dom Pedro II, in the sense center - district, and Avenida Nossa Senhora de Fatima and the Netherlands in order Camilo neighborhood-center.

The corridor continues to the junction of the Universidade Federal da Paraíba, featuring three-way lanes for mixed use in each direction, favoring the flow of vehicles.

It is noticed that the Avenue Dom Pedro II receives a large amount of cars to be a major structural axis transport in the city of Joao Pessoa, is the main connection to the central area of South Zone.

This research proposes to: define the route and operational aspects of the VLT line, considering the configuration of João Pessoa and the demands for public transportation in the city, specifically along the Corridor of Avenue Dom Pedro II, an integrated system along the line of the trunk VLT, with the following modes: train, bus, bicycle and foot, a model that fits the VLT intra-urban fabric, thus improving the accessibility, mobility and urban quality of life.

\section{Methods}

This study is an exploratory and descriptive research that seeks solutions to improve mobility, accessibility and urban quality of life, in João Pessoa (PB), specifically along the Corridor of Avenue Dom Pedro II.

\subsection{Procedures and steps of the research}

Initially a survey was conducted as documented on the subject. Subsequently a survey was conducted on the system metroferroviário, attractions, you see interviews with members of the CBTU. We then carried on a data collection STTRANS in which we obtained quantitative data that helped in deepening research on the public transport system of Joao Pessoa. These data assisted in the calculation of estimated customer demand along the corridor of Avenue Dom Pedro II.

The author of this work made a trip to Brasilia (DF), to better understand the operation of the line and system integration project for implementation of the VLT of the Federal District, through visits and questions with members responsible for work in that Metro . Later, it came to attend the XXII General Assembly of the Asociación Latinoamericana de Metros y Underground (ALAMYS), where he received important support, which contributed to the analysis of the subject, such as the strong influence of the VLT, in Brazil and worldwide.

Field research was conducted with photographic survey and metric (digital tape), in two elective sections for preparation of the draft: one in the hallway of Avenue Dom Pedro II and another in the Street: Bank Accioly Waldemar de Mesquita. Later, he made the preliminary study of the seasons, in order to program needs, preliminary design, architectural advantage, volume, among others. The primary methodological concern - the intermodal integration. Soon the trunk line could not exist alone without the power to the system bus. Based on this, devised a possible line up cycling and bus to integrate with the tramway system. 


\section{Results}

\subsection{Considerations}

After 60 years with the construction of the campus population expansion of John Person, occurred at an accelerated rate in the south and southeast axis, and still observed a large city development and traffic jam in the direction of this vector. This research resulted in the development of a proposed public transportation system for the city of João Pessoa (PB), based on VLT, along the corridor Avenue Dom Pedro II of linking the Southeast Center.

[1] The number of private cars in the state capital grew $16 \%$ in 2008 .

[2] The fleet of vehicles in Brazil has doubled over the past 10 years, which resulted in approximately 59 million vehicles in 2009. In the period 2000 to 2009 , the average annual growth of the fleet is approximately $8.0 \%$. In the state of Paraiba, the increase was even greater, the average rate was approximately $14.4 \%$, which totaled about 612 thousand vehicles in 2009, of which 204000 are licensed in Joao Pessoa.

In the city of Joao Pessoa, in particularly, is finding the large increase in the use of private cars, traveling on public roads and the main city center, thus demonstrates that, especially in times of "peak", signs of saturation, congestion, pollution, slow traffic, dehumanization in urban space and considerable social costs to the population.

[6] In December 2000, the city had 100,428 cars, while in August 2008, there have been 180,620 vehicles circulating on the streets of the capital. The increase in motorization in cities has increased levels of atmospheric air pollution through the release of carbon monoxide, harmful substance people, causing respiratory problems, and other subsequent allergic.

\subsection{Factors influencing the loss of urban mobilityna}

The cause of the problems related to the loss of urban mobility stems from several factors, one of the key is in the valuation of private motorized transport, which is being encouraged today to establish itself as synonymous with "progress and social status." Figure 1.
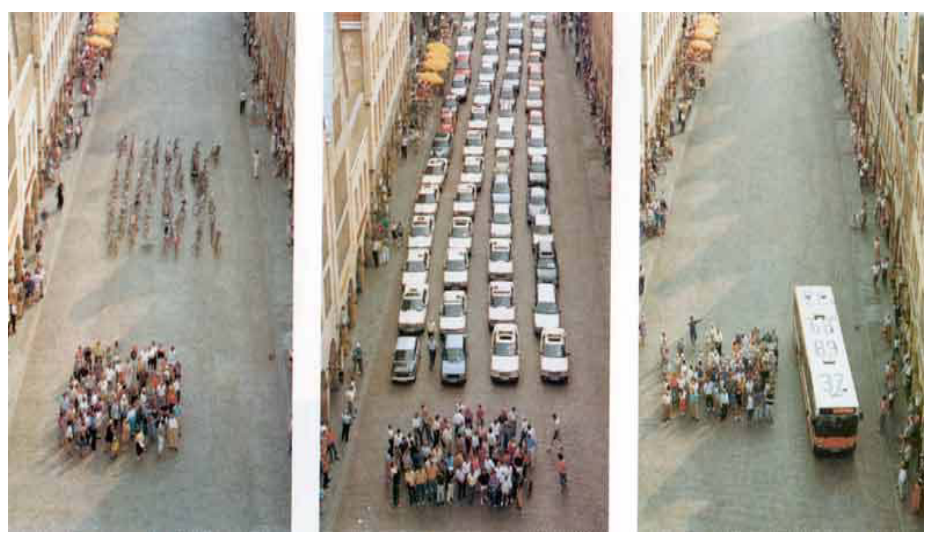

Fig. 1 - Space occupancy: 72 people on bicycles, in cars and buses.

Source: Assis, Uiara. Public passenger transport based on the VLT, along the Avenue Corridor D. Pedro II. Joao Pessoa (PB), 2009.

\subsection{Definition and operational aspects of the course}

The public transportation line was defined, delimiting a "direct area of influence" within this area, it has important centers of attraction in the city, such as universities, hospitals, shopping malls, trade and services, to provide a satisfactory coverage of populated areas and ensure a good accessibility to the transport system.

The line is classified as radial, it connects the Jardim University City and its surrounding neighborhoods (Anatolia, Banking and Mangabeira) in the downtown area. It sets up a system of trunk line feeder, where the trunk line is established by public transport corridor, (represented by the diagram in green) that will be fueled by the bus system (represented in blue) offering points of bus stops, close to tramway stations, to ensure ultimate ease and speed the transfer to the destination. Line has two major points of integration, one located near the university, where the user can use the VLT towards the central area, or make the transfer, and catch the bus to Riverside runners or Pessoa. Figure 2. 


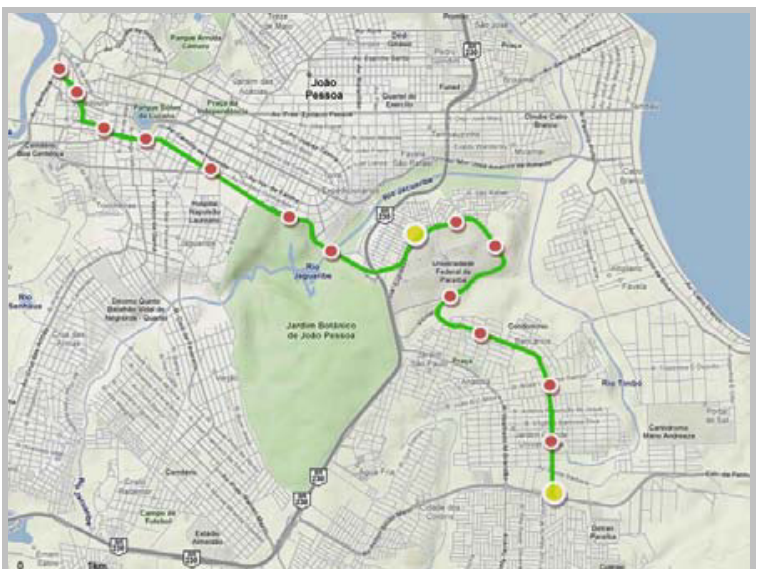

Fig. 2 - Complete range of the VLT and its line of worksta tions

Source: Assis, Uiara. Public passenger transport based on the VLT, along the Avenue Corridor D. Pedro II. Joao Pessoa (PB), 2009.

\subsection{Integrated: VLT-bike-bus}

To illustrate the hierarchy of transport, a system of physical integration unit has developed from a diagram where the line is shown being fed by the VLT bus lines-thorities, and in parallel the line cycling, with bike racks next season.

The proposed line has approximately $12 \mathrm{~km}$ long and has fifteen stations. Of these, two intermodal terminals are represented by the color yellow on the map, and thirteen stations VLT, working with the environment, aiming at seamless integration of adjacent areas, by treating the sidewalks, and feeder bus lines and bike racks. Figure 3.

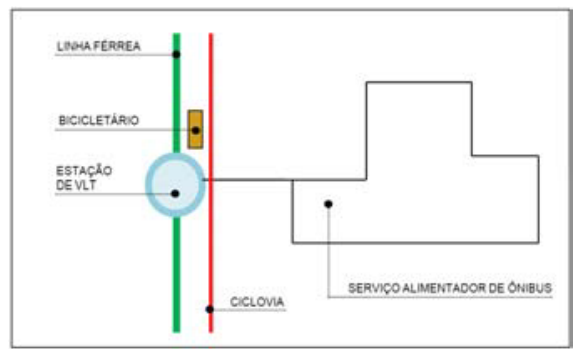

Fig. 3. Integration between the modes of transmission System VLT-sized public bike-bus

Source: Assis, Uiara. Public passenger transport based on the VLT, along the Avenue Corridor D. Pedro II. Joao Pessoa (PB), 2009.

\subsection{Features of the capacity between the modes}

Measures on the transport system can influence the dynamics of the city, to the health of the population, because with a less polluting transportation, will reduce the rates of respiratory and cardio-vascular diseases caused by pollution from large centers in cities. [4] Environmental factors play also a significant impact on health. Usually associated with indoor air pollution and environmental, they cause more than a third of diseases resulting from infection of the respiratory system or infer.

A VLT at full capacity can transport up to 600 people, while it would take 150 cars and 10 buses to transport the same amount of people. Figure 4.

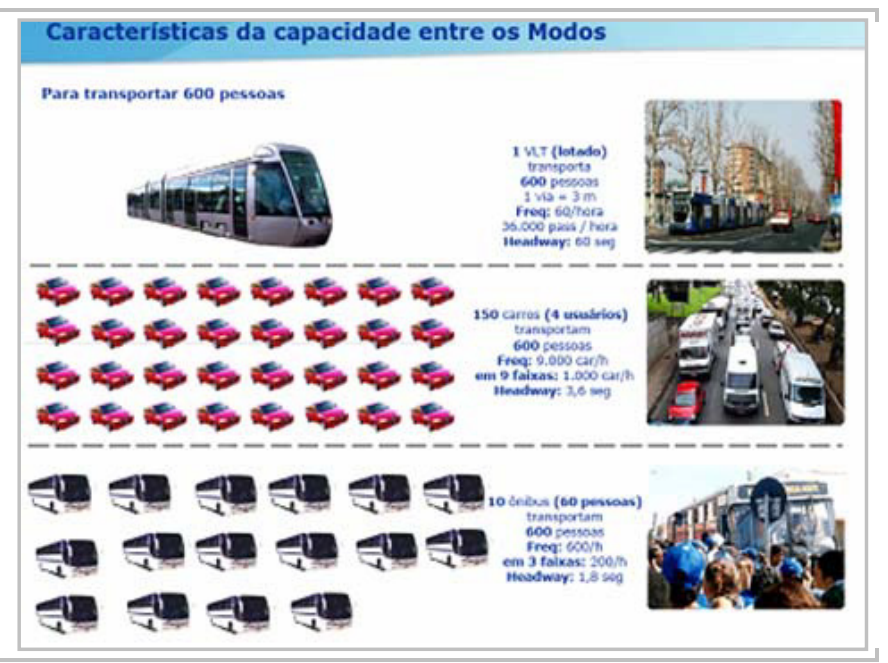

Fig. 4 Characteristic of the capacity between modes Source: Assis, Uiara. Public passenger transport based on the VLT, along the Avenue Corridor D. Pedro II. Joao Pessoa (PB), 2009.

\subsection{The model proposed VLT}

The vehicle features wide doors with large windows and double leaf, providing a greater interaction with the external environment, and make the trip more enjoyable by observing the urban landscape. Figure 5. 


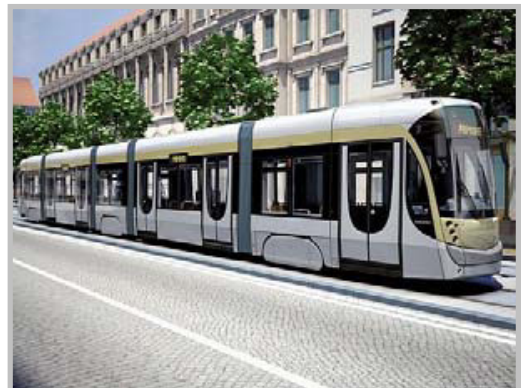

Fig. 5 Model proposed VLT

Source: Assis, Uiara. Public passenger transport based on the VLT, along the Avenue Corridor D. Pedro II. Joao Pessoa (PB), 2009.

\section{Discussion}

\subsection{The issue and the issue of urban transport}

Urban transport plays an important role in socioeconomic scenario of the country, it interacts directly with the development and organization of cities, with direct impacts on use and land cover in urban efficiency and quality of life. Some time ago, the industry is showing signs of crisis, represented by the systematic loss of demand in the regular transportation. $[5]$.

In recent years the offsets for cars, alternative transport, among others, are considered more attractive than the regular public transport, the latter considered by many people, inefficient, inflexible and of poor quality. This reduces the efficiency of urban, causing decreased mobility and accessibility, lack of public policies more "aggressive", which prioritize the collective means of transport.

Currently, it requires the creation of effective and applicability of continuous interaction and coordination among the transportation, transit, land use and environment. A good strategic plan, developed by multidisciplinary teams and interagency, with actions between the functions of urban housing, transportation and transit, basic infrastructure (roads and health) will bring great solving of the problems now facing.

\subsection{Main advantages of the VLT}

Because they are made of lighter cars and the latest technology for traction control and suspension system, the trams allow a quiet operation with low vibration and bump;

- The micro-processor control ensures efficient braking comfortable and matches with a lower consumption of materials and half the time; - Fuel consumption is around $40 \%$ less than the systems of locomotive-hauled;

- With respect to environmental pollution, protect the trams are submitted to EURO-3 standard ensures that levels of particulate emissions into the atmosphere when diesel traction, are within established as acceptable by the Kyoto Protocol.

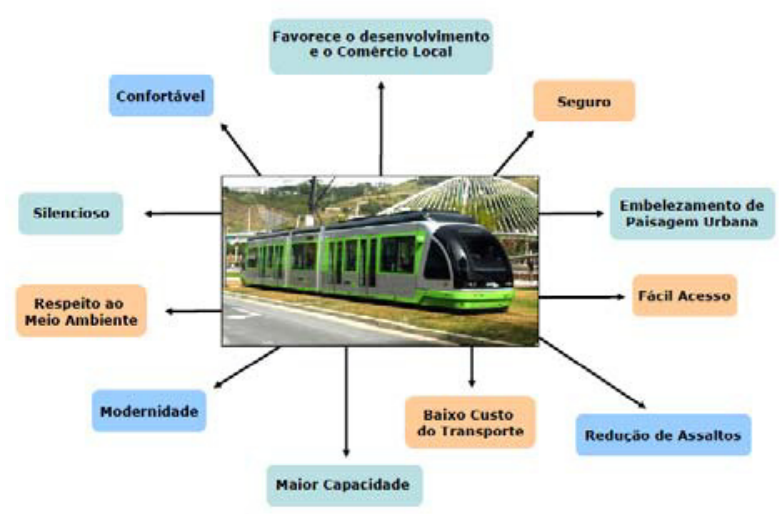

Fig. 6. Advantages of the VLT.

Source: Assis, Uiara. Public passenger transport based on the VLT, along the Avenue Corridor D. Pedro II. Joao Pessoa (PB), 2009.

\subsubsection{Flexibility}

Developed and manufactured in modular technology, the trams can be quickly replaced during maintenance or modernization. As can also go gradually increasing its capacity, according to the need for expansion of passenger demand, by inserting intermediate modules.

\subsubsection{Impact on the growth of privat Individual transport in the man-society-nature}

[7] By producing a road system suitable for personal transportation, the state increases the gap between the conditions of individual and collective transport, thus increasing the gap between the travel conditions of social classes, improving the accessibility of each (ie their locations) rather than the detriment of others.

The excessive increase of private motor vehicles has caused a situation of conflict and concern in the man - society - nature. 


\subsection{VLT Trend in Brazil}

Brazil has a tendency for the VLT, as a means of urban transport, with projects to be implemented in several cities: Santos - SP, Brazil, Vitória, Goiânia, Rio de Janeiro and depending on the political will and resources for the construction of work, too, in João Pessoa (PB).

\section{Conclusion}

Currently, the mobility of people in the intra-urban space is being threatened by congestion, pollution resulting from the appreciation of the culture of personal transport and the precariousness of public transportation.

In the city of João Pessoa (PB), the subject of this finding for these disorders, resulting in people on the streets and especially on workers who move daily from their homes to their places of work, stress and respiratory problems arising pollution from excess circulating private cars on public roads and slow to get to their destinations.

This research demonstrates the feasibility of implementing the tramway along the Corridor of Avenue Dom Pedro II, in João Pessoa (PB), and could therefore, a good transportation network for use of the population, reduce the number of vehicles on the road, minimize pollution and, consequently, optimize mobility and urban sustainability. Thus users will move from its point of origin to its destination with speed comfort and safety.

\section{References}

[1] L. Bonadio. Number of cars per thousand inhabitants is between 1997 and 2007. New York: Transportation, April 4, 2009 [2] DENATRAN. Statistics: vehicle fleet. National Traffic Department. Brasília, 2010. http://www.denatran.gov.br/frota.htm/. (Accessed 3/28/10).

[3] J. A. Mousset. Feasibility study for the inclusion of line light rail transit (LRT) in João Pessoa, Paraíba. John Person: City of João Pessoa - SEPLAN, 2007, p.63.

[4] World Health Organization Draft Eleventh General Programme of Work 2006-2015: executive summary. RC/2005/2, July 25, 2005.

[5] Program Macro Objectives. Improving the quality of transport and urban transit. Available at:

$<$ http://aval ppa2000.planejamento.gov.br/content/programas/24/ macro24.htm>. Accessed: March 10, 2009.

[6] Oversight of Transportation and Transit (STTRANS) - Joao Pessoa. STTRANS -. Scenes now common in large cities are listed in João Pessoa. Available at: http://db5.skyscrapercity.com/showthread.php?t=733890\&page $=2$ 6> Access: 04/14/2009.

[7] F. Villacis. Intra-urban space in Brazil. 2nd ed. São Paulo: Studio Nobel: FAPESP: Lincoln Institute, 2001. 